ISSN: 1130-3743 - ISSN electrónico: 2386-5660

DOI: http://dx.doi.org/10.14201/teoredu2015272161183

\title{
LA FORMACIÓN LECTORA Y LITERARIA EN CONTEXTOS MULTICULTURALES. UNA PERSPECTIVA EDUCATIVA E INCLUSIVA
}

\author{
Reading and literary training in multicultural contexts. \\ An inclusive educative perspective
}

\section{L'apprentissage de la lecture et la littérature dans des contextes multiculturels. Une perspective éducative inclusive}

Josep BALLESTER ROcA y Noelia IBARRA RUIS

Universitat de València. Departament de Didàctica de la Llengua i la Literatura. Facultat de Magisteri. Avenida Tarongers, 4.46022 Valencia.

Josep.ballester@uv.es; Noelia.ibarra@uv.es

Fecha de recepción: marzo de 2015

Fecha de aceptación: junio de 2015

Biblid [(1130-3743) 27, 2-2015, 161-183]

\section{RESUMEN}

Los autores exponen el potencial de la educación lectora y literaria en cuanto a su función en contextos multiculturales y plurilingües se refiere y preconizan su importancia no sólo en la adquisición y desarrollo de hábitos de lectura estables, sino como un pilar esencial en el compromiso de la construcción de sociedades más igualitarias y democráticas. En oposición directa al gran número de agoreras voces que alertan sobre los peligros del aumento de las migraciones y sus consecuencias en forma de alumnado inmigrante en las aulas de los diferentes niveles educativos del Estado español, los investigadores abogan por las posibilidades de la didáctica de la 
literatura y de la lectura en el descubrimiento y la consolidación de las competencias lectora, literaria e intercultural y, por tanto, en este sentido, revelan la magnitud del texto literario desde una perspectiva educativa e inclusiva en la construcción de la ciudadanía.

Palabras clave: educación literaria; formación lectora; diversidad; inmigración; educación intercultural; inclusión; competencia lectora, literaria e intercultural.

\section{SUMMARY}

This article exposes the potential of reading and literary education in multicultural and multilingual contexts, as well as, recommend its importance not only on the acquisition and development in stable reading habits, but as an essential foundation for the construction of much more equal and democratic societies. Directly opposed to a great numbers of pessimistic voices that alert about the dangers in the increasing migratory movements, and their consequences as migrating students in all the different levels at Spanish schools in the country. Researchers stand for the possibilities of literature and reading didactics in the development and consolidation of reading, literary and intercultural competences, and therefore, in this sense, reveal the magnitude of the literary text from an educative and inclusive perspective that allows the construction of the citizenship.

Key words: literary education; reading training; diversity; migration; intercultural education; integration; reading; literary and intercultural comprehension.

\section{SOMMAIRE}

Les auteurs présentent le potentiel de la lecture et de l'éducation littéraire et son rôle dans des contextes multiculturels et multilingues, en plaidant son importance non seulement dans l'acquisition et le développement des habitudes de lecture stables, mais aussi comme un pilier essentiel de l'engagement pour la construction de sociétés plus démocratiques et égalitaires. S'opposant directement au grand nombre de voix menaçantes qui avertissent des dangers de l'augmentation de la migration et de ses conséquences sous la forme d'élèves immigrants dans les salles de classe des diverses niveaux d'enseignement de l'État espagnol, les chercheurs préconisent les possibilités de l'enseignement de la littérature et de la lecture dans la découverte et la consolidation des compétences de lecture, littéraires et inter culturelles. Par conséquent, dans ce sens, ils révèlent l'amplitude du texte littéraire dès une perspective éducative et inclusive dans la construction de la citoyenneté.

Mots clés: éducation littéraire; apprentissage de la lecture; diversité; immigration; éducation inter culturelle; inclusion; les compétences de lecture, littéraire et inter culturelle. 


\section{INTRODUCCIÓN}

La lectura y, en especial, la lectura literaria constituye uno de los ejes de intervención educativa más estudiados en el inicio del segundo milenio; su promoción, las destrezas, las capacidades, las habilidades y las competencias necesarias para la lectura, entendida desde una perspectiva crítica e interdisciplinar, así como la adquisición y el desarrollo de hábitos lectores, como base para la superación exitosa por parte del alumnado de los diferentes niveles educativos, suponen puntos de confluencia asumidos por la comunidad educativa e investigadora.

Sin embargo, su relevancia no se agota en la progresión del alumnado por las diferentes etapas académicas, puesto que la lectura, y, sobre todo, la lectura literaria, trasciende con creces los contenidos de una única materia, dado que comprende la educación integral del ser humano y el aprendizaje a lo largo de la vida (life long learning). A tal efecto, pensemos que la lectura y, en especial, la lectura literaria, entre otras funciones, permite dotar al lector de los instrumentos cognitivos para comprender el mundo de forma crítica y asumir la diversidad como rasgo consustancial a todo colectivo, por lo que éste podrá ejercer su ciudadanía de forma activa y colaborar en la construcción de sociedades más igualitarias y democráticas. En este sentido, podemos sin duda definirla como una herramienta privilegiada para la educación intercultural por su extraordinario potencial para la construcción de la ciudadanía.

Uno de los efectos más perversos de la globalización como fenómeno socioecónomico y, sobre todo, ideológico radica en la aparente naturalización del incremento de los movimientos migratorios y sus consecuencias en la redefinición de la geografía sociopolítica mundial, con particular incidencia en la europea. El aumento de las migraciones y su incidencia en la rearticulación de las sociedades contemporáneas invalida cualquier política educativa que obvie las necesidades de los contextos multiculturales y multilingües.

La globalización y, como consecuencia directa, los movimientos migratorios generados a partir de su vertiginosa expansión han originado sustanciales modificaciones en la sociedad contemporánea. Nuestro entorno se modifica a un ritmo trepidante y entre estas transformaciones destaca, sobre todo, el tránsito de las sociedades aparentemente monoculturales hacia una sociedad multicultural. De hecho, el claro intento de dibujar y legar sociedades monoculturales a las futuras generaciones se descubre como una evidente falacia, sobre todo, en los últimos decenios del siglo xx y principios del siglo xxI en el Estado español, pues su geografía nos revela como característica definitoria la eclosión de la diversidad cultural. El mapa educativo español reitera esta constante, poblado por la pluriculturalidad heterogénea que encontramos en las aulas de los diferentes niveles de la escolaridad.

Las cifras constatan este tránsito acontecido en aproximadamente un cuarto de siglo en el Estado español. Así, el estudio del inicio de la década de los noventa nos desvela un porcentaje de inmigración cifrado en un 2\% de la población, mientras que, a principios de la segunda década del siglo xxI, la inmigración se cuantifica 
en un $10 \%$ de la población, de acuerdo con los informes facilitados por el Ministerio de Trabajo e Inmigración (2010), ahora Ministerio de Empleo y Seguridad Social (2013). Por su parte, el último informe del 2013 nos dice que el número de extranjeros con certificado de registro o tarjeta de residencia en vigor corresponde a 5.503 .977 personas.

Si consideramos el régimen jurídico de aplicación, 2.702.867 personas corresponden a Régimen Comunitario, es decir, el 49,11\% del total, y 2.801 .110 personas se engloban en el Régimen General (50,89\%). Por tanto, con respecto a 31 de diciembre de 2012, se ha producido un aumento del 1,70\%, porcentaje que en cifras se traduce en 92.054 personas más, calificadas con el término de «inmigrante» en la estadística. Respecto al Régimen General, es decir, personas que no provengan de la Comunidad Europea, se constata un 0,51\%, esto es, 14.192 extranjeros con respecto al trimestre anterior y un 1,62\% correspondiente a 44.534 personas desde diciembre de 2012. A 30 de diciembre de 2013, el número de marroquíes en Régimen General asciende a 849.946, esto es, el 30,35\% del total en este régimen. Le siguen Ecuador, Colombia y China.

En cuanto a los lugares de procedencia más repetidos, los datos muestran el predominio de cinco países: Rumanía (925.140), Marruecos (888.937), Ecuador (390.034), Colombia (270.335) y Reino Unido (255.135), que conjuntamente representan el 49,60\% del total de extranjeros en España. Por otra parte, respecto a la ubicación de residencia más elegida en el Estado español, destaca en primer lugar Cataluña, en la que residen 1.261.416 extranjeros con certificado de registro o tarjeta de residencia en vigor; en segundo lugar, la Comunidad de Madrid con 938.781 residentes, y, a continuación, Andalucía y la Comunitat Valenciana que superan los 700.000 residentes, mientras que el resto de comunidades autónomas se sitúa por debajo de los 300.000 extranjeros.

Más allá de cifras y estadísticas, en el ámbito educativo el crecimiento de los movimientos migratorios en las últimas décadas y sus consecuencias puede considerarse como uno de los retos pedagógicos clave del siglo xxI. Ante esta reestructuración de la sociedad anteriormente descrita, cabe pues preguntarse cómo abordar el diálogo intercultural y, sobre todo, cómo responder a la complejidad multicultural que en nuestros días puebla las aulas de los diferentes niveles educativos.

Si asumimos la importancia de la lectura y en especial de la lectura literaria y la escritura más allá de las meras destrezas de la alfabetización funcional, esto es, como factores clave de las posibilidades de desarrollo del ser humano en los diferentes ámbitos que componen su existencia, pues de ellas puede depender tanto el éxito curricular como el laboral o las relaciones sociales, entenderemos la relevancia de vincular de forma explícita la educación lectora y literaria con la educación intercultural, e incluso, un paso más, inclusiva. De hecho, el reconocimiento de la multiplicidad de escenarios educativos y la diversidad de los lectores mutila la concepción de las prácticas lectoras como un elemento casual que dependerá únicamente del entorno en el que se produzcan para la creación o no de lectores. Por el contrario, en este contexto, la educación literaria intercultural puede desempeñar 
un papel esencial tanto en la gestación de la identidad individual y colectiva del lector como en la comprensión crítica de la realidad circundante que le facilita, pero también de los otros procedentes de realidades, lugares y culturas diferentes a la propia o de la alteridad existente en todo núcleo social y, por tanto, en la formación de la ciudadanía y en la construcción de sociedades democráticas y plurales.

\section{ALGUNAS NOCIONES Y CONCEPTOS RELACIONADOS CON LA FORMACIÓN INTERCULTURAL}

Con relativa frecuencia, encontramos una marcada indefinición en el empleo de los términos relativos al tema que nos ocupa, por este motivo, dada la complejidad de los términos implicados, en primer lugar, delimitaremos el significado de los más relevantes para nuestro trabajo. De hecho, en numerosas ocasiones se utilizan de forma indistinta significantes que aluden a realidades diferentes, así, el debate pedagógico equipara dos conceptos diferentes: la diversidad sociocultural y la inmigración. A tal efecto, nos parece pertinente subrayar que la diversidad trasciende los límites de la migración, puesto que representa un rasgo consustancial a toda comunidad y, sobre todo, inherente a nuestras sociedades modernas, construidas históricamente sobre diferentes procesos migratorios.

El término diversidad presenta, además, diferentes significados, dado que no sólo alude a la lengua, la religión o la procedencia, sino también a variables como el sexo, la edad, la clase social e, incluso, las diferencias entre medio rural y urbano o la estratificación social. Por su parte, Canto (2003, 100-101) postula que la «diversidad del ser humano es compleja y múltiple», por lo que la identidad procede de la pertenencia de cada uno a varios grupos sociales. Para esta autora la diversidad de las aulas procede de la conjunción de diferentes factores: a) diferencias raciales y pertenencia a una cultura; b) pertenencia a diferentes tipos de estructuras familiares; c) diferencias de género; d) pertenencia a una determinada clase; e) opción religiosa o carencia de ésta; f) diferencias en cuanto a capacidades, actitudes y destrezas.

En el ámbito educativo, la escuela española no se ha caracterizado precisamente por la apertura en su currículo a las múltiples diversidades que atraviesan la composición de su alumnado, sino precisamente por su tendencia contraria: la integración y la asimilación de los colectivos minoritarios a los rasgos del grupo hegemónico. Progresivamente, el sistema escolar español ha ido evolucionando en su tratamiento de la diversidad, desde la consideración de los denominados grupos «minoritarios» en la educación compensatoria, hasta el auge de la reflexión pedagógica sobre el paradigma pedagógico más adecuado e inclusivo.

En los últimos tiempos, la presencia en las aulas de un alumnado cada vez más heterogéneo, de origen étnico y cultural diverso, demanda una enseñanza que atienda a esta nueva composición del grupo clase. El pluralismo cultural constituye en palabras de Gimeno Sacristán «un reto en muchos aspectos al pensamiento dominante, a los supuestos de la educación y sus prácticas» $(2001,182)$. Un reto que debemos asumir en todas las áreas y disciplinas curriculares, ya que 
la educación ha sido y sigue siendo un espacio privilegiado para fomentar el respeto a los otros, sean diferencias étnicas, sociales, culturales o de cualquier tipo. El concepto de ciudadanía debe concebirse necesariamente como abierto e inclusivo (Arnáiz y Escarbajal, 2012; Leiva, 2011; Naïr, 2010; Portera, Dusi y Guidetti, 2010). Sin embargo, pese a la asunción consensuada de la diversidad sociocultural como elemento omnipresente del entorno contemporáneo, su tratamiento dista todavía considerablemente de resultar generalizado.

En la actualidad, la observación en las aulas de los diferentes niveles educativos nos devuelve una nueva realidad a la que responder: la configuración de un mosaico heterogéneo marcado por la diversidad cultural. En nuestro país, la situación reitera constantes apuntadas en otros países europeos, pues nos encontramos con alumnos y alumnas provenientes de diferentes culturas, esencialmente, de Asia, América Central y del Sur, África, en especial del Magreb, y una presencia importante de la Europa comunitaria.

El análisis de los diferentes informes realizados en torno a la presencia de los estudiantes extranjeros en los niveles no universitarios en el sistema educativo español en la última década nos permite sintetizar las siguientes conclusiones: a) la escolarización de más de tres cuartas partes de este alumnado corresponde a centros públicos; b) la zona de procedencia predominante es América Central y del Sur, seguida de África; c) la existencia de notables diferencias en la distribución de esta población según las comunidades autónomas; d) el nivel educativo en el que encontramos más población extranjera escolarizada en la actualidad es Educación Primaria, sin embargo, en los últimos tiempos se está produciendo un incremento progresivo en la ESO a tenor de la evolución de los datos (CIDE, 2007; Ministerio de Educación, Cultura y Deporte, 2013).

Por este motivo, ante tal redefinición del mapa escolar en los distintos niveles, el sistema educativo y, en un plano más concreto, las aulas, poseen un papel fundamental no solo en la construcción, sino en el reconocimiento diverso y múltiple de las identidades, como apuntan Rodríguez Lestegás y García Bernedal $(2008,9)$ :

La escuela debe ser una forma de vida social, es decir, una institución que se convierta, ciertamente de manera temporal y provisional, en un lugar de experiencia colectiva para los sujetos que acuden a ella y a los que ofrezca la oportunidad de ser considerados miembros de la sociedad y de desarrollar su sentido de pertenencia e identidad. [...] El insuficiente despliegue de los sentimientos de adhesión y lealtad entre los individuos que conforman las multiculturales sociedades postindustriales [...] la creciente inmigración y el avance de la xenofobia fuerzan la necesidad de diseñar nuevas opciones educativas bajo el estandarte de la interculturalidad.

La respuesta desde el ámbito pedagógico viene determinada por los objetivos comprendidos en el seno de la denominada educación intercultural, como clave para el diálogo intercultural y el conocimiento entre culturas. La denominada educación intercultural intenta responder en la práctica a la convivencia de diferentes grupos étnicos y culturales en el seno de una sociedad dada. Si bien 
existen diferentes términos para referirse a las propuestas pedagógicas ligadas a la diversidad cultural presente en las clases, la marcada preferencia del sintagma «educación intercultural» frente a otros términos como "pluriculturalismo» o «multicultural" responde a un enfoque sustancialmente diferenciado. Concretamente, en el ámbito europeo no anglosajón, la multiculturalidad se comprende como un enfoque contrapuesto a la noción de interculturalidad con el objeto de «dotarle al segundo de una mayor fuerza positiva a la hora de caracterizar el fenómeno» (Bartolomé, 2001, 76).

La distinción terminológica diferencia también el campo de actuación de cada uno, pues en el ámbito americano la educación multicultural se extiende a todo tipo de colectivos, desde el género, la clase social o las personas discapacitadas, mientras que en Europa esencialmente se ha concentrado en grupos étnicos y culturales que como inmigrantes llegaban a diferentes países.

Además, el término multicultural resulta meramente descriptivo, esto es, se limita a la delineación de la realidad de las sociedades existentes en las distintas culturas, a diferencia de intercultural, eminentemente normativo, puesto que implica un proceso de intercambio e interacción comunicativa deseable en las sociedades multiculturales (Ballester, 2007b; Sales y García, 1997).

Quizá una de las definiciones más completas proceda de Aguado (2003, 63), para la que educación intercultural significa:

La reflexión sobre la educación, entendida como elaboración cultural, y basada en la valoración de la diversidad cultural. Promueve prácticas educativas dirigidas a todos y cada uno de los miembros de la sociedad en su conjunto. Propone un modelo de análisis y de actuación que afecte a todas las dimensiones del proceso educativo. Se trata de lograr la igualdad de oportunidades (entendida como oportunidades de elección y de acceso a recursos sociales, económicos y educativos), la superación del racismo y la competencia intercultural en todas las personas, sea cual sea su grupo cultural de referencia.

La pregunta, a partir de las líneas de actuación esbozadas en las clarificadoras palabras de Aguado, sería, evidentemente, cómo llevar a la práctica el enfoque intercultural, pues, en la actualidad, y pese a la urgencia y relevancia de su praxis, todavía no tiene una auténtica realización en las aulas españolas y europeas.

En este sentido, la educación intercultural asume la diferencia cultural entre individuos y grupos como foco central de análisis y actuación educativa. Desde esta postura pedagógica, la diversidad cultural es considerada como una valiosa fuente de enriquecimiento para todos los colectivos implicados y en modo alguno puede suponer un peligro o una amenaza para la identidad de alguno de estos grupos sociales. Además, tal y como se desprende de la aseveración anterior, la educación intercultural se destina a todos los componentes de la comunidad educativa, dado que únicamente así puede constituirse en un instrumento de superación de la exclusión sociocultural que la globalización implica. 
De esta manera, la educación intercultural constituye una notable evolución respecto a toda una serie de actitudes educativas resumidas en la denominada educación monocultural. Como alternativa crítica a tal postura pedagógica, la educación intercultural denuncia la incoherencia de una praxis educativa destinada únicamente a determinados sectores sociales y no al conjunto de la comunidad. Asimismo, se distancia nítidamente de la propuesta culturalista, puesto que el interculturalismo supone la asunción de la relevancia de la diversidad como positiva y no como un problema de compleja resolución (Besalú y Tort, 2009; Malgesini y Giménez, 2000; Naïr, 2010).

En última instancia la educación intercultural persigue la promoción de prácticas educativas destinadas a todos y cada uno de los integrantes de la comunidad educativa para garantizar la igualdad de oportunidades y la superación de actitudes racistas a través del desarrollo de la competencia y el diálogo intercultural.

Esta exigencia del diálogo entre culturas como pilar esencial de toda sociedad contemporánea digna de ser calificada como democrática se refleja en diferentes actuaciones estatales e internacionales, como, por ejemplo, en la declaración de la Comisión Europea del Año Europeo del Diálogo Intercultural 2008. Entre sus principios fundamentales destaca la construcción y la consolidación de una ciudadanía europea comprendida de manera crítica y cimentada en la conciencia de la importancia de ejercer un papel activo en la construcción de una sociedad caracterizada por el diálogo entre culturas.

Desde esta dimensión, el diálogo intercultural adquiere una relevancia esencial como instrumento de conocimiento y enriquecimiento cultural mutuo que trasciende las fronteras espaciales y culturales, dado que defiende la convivencia entre culturas en un mismo espacio geográfico a partir del respeto a derechos fundamentales de los seres humanos. Asimismo, subraya la contribución de las diferentes culturas a la creación de un patrimonio e imaginario colectivo compartido por todos los ciudadanos.

\section{LA FORMACIÓN LECTORA Y LITERARIA EN CONTEXTOS MULTICULTURALES Y PLURILINGÜES}

En el ámbito educativo, los interrogantes ante la diversidad se multiplican, hasta el punto de ser calificada en el Informe Delors como el reto pedagógico del siglo XXI, pues, en definitiva, ¿qué respuestas puede ofrecer la educación a las transformaciones sociales de la contemporaneidad? Delors contesta mediante cuatro pilares básicos, de igual relevancia y constantes a lo largo de la vida: a) aprender a conocer; b) aprender a hacer; c) aprender a vivir juntos y, finalmente; d) aprender a ser, progresión fruto de los cuatro aprendizajes anteriores (1996, 75 y ss.).

Esta concepción de la función pedagógica apunta, en primer lugar, hacia la formación integral del alumno, como base del sistema social y, sobre todo, permite atender al reto de nuestras sociedades multiculturales: aprender a vivir juntos, aprender a vivir con los otros. Nos encontramos, en esencia, ante el descubrimiento 
del otro a partir del conocimiento de uno mismo y del mundo por medio del diálogo, en el que la literatura juega un papel esencial desde las primeras etapas vitales.

A tal efecto, tanto en un nivel general, toda España, como en un nivel de comunidades autónomas, nuestras leyes educativas dictaminan netamente la obligatoriedad de atender a la diversidad cultural de los discentes que progresivamente caracteriza las aulas del siglo XXI. Entre sus fines específicos, la legislación educativa subraya la formación integral del alumnado y, sobre todo, en el respeto de los derechos y de las libertades fundamentales, en la igualdad efectiva entre hombres y mujeres, así como en la superación de los comportamientos y actitudes discriminatorias de toda índole y en la igualdad efectiva de oportunidades.

De acuerdo con estos fines se establecen una serie de medidas concretas, desde la atención al alumnado con necesidades educativas específicas y, entre este colectivo, los alumnos y alumnas de incorporación tardía al sistema educativo español por proceder de otros países. Como también en el diseño de instrumentos curriculares específicos, tales como las competencias básicas que el alumnado debe adquirir una vez finalizada la etapa y, entre éstas, la competencia en comunicación lingüística, social y ciudadana, cultural y artística y digital.

Simultáneamente, instituye el Plan de Fomento de la Lectura, cimentado en la necesidad imperiosa de impulsar el hábito lector estable más allá de las lecturas prescriptivas de aula y, fundamentalmente, con un objetivo básico: la formación de lectores competentes en todas las áreas, no solamente las lingüísticas, así como en los distintos niveles educativos.

En este sentido, la literatura desempeña un papel fundamental no sólo como fuente esencial de conocimiento de otras culturas y realidades diferentes a la propia del alumnado, sino también en la promoción de la convivencia intercultural. Asimismo, ejerce una función destacada en la adquisición y en el desarrollo de las competencias básicas establecidas por el sistema educativo: la competencia en comunicación lingüística, la competencia cultural y artística y, sobre todo, la competencia social y ciudadana, puesto que persigue dotar al alumnado de los recursos básicos para comprender la realidad social en la que se encuentra inmerso. En última instancia, se trata, efectivamente, de formar ciudadanos en el sentido crítico del término, esto es, personas capaces de ejercer la ciudadanía de manera comprometida y responsable en la sociedad actual, así como contribuir decisivamente a la mejora de la convivencia y el respeto entre culturas.

Así, la literatura y, fundamentalmente, la Literatura Infantil y Juvenil -en adelante LIJ-, como aquella destinada de manera específica al niño y al joven en tanto receptores privilegiados de ésta en los diferentes niveles educativos, proporciona a su lector los referentes de la cultura en la que va a insertarse y constituye, por tanto, un enriquecedor instrumento de socialización. Además, las aulas se encuentran pobladas por niños y jóvenes de diferentes nacionalidades que, más allá del conocimiento académico, demandan poder compartir sus vivencias y culturas en un clima propicio. 
El texto literario cobra desde esta perspectiva toda su vigencia como instrumento cognoscitivo desde el que aproximarnos a aquel que es diferente a nosotros, tanto el extranjero como todos los otros existentes en cada sociedad. A partir del texto literario y sobre todo de la LI podemos aproximar al alumnado a la realidad en la que se encuentra inmerso y desde ésta analizar los principales núcleos de debate en torno a la interculturalidad con la finalidad de la formación de posturas críticas en torno a actitudes discriminatorias como el racismo, la xenofobia o cualquier perpetuación de estereotipos de raza o etnia (Ibarra, 2007 y 2008; Short, 2009).

En este proceso, el foco de interés esencial es el texto literario per se, tanto como recurso didáctico y pedagógico de primer orden para las aulas pluriculturales, como también para la promoción de procesos de formación, análisis y reflexión del profesorado con enfoque intercultural y, en esencia, de toda la comunidad educativa.

Durante la lectura, el receptor activa su competencia literaria y en el seno de ésta, su intertexto (Mendoza, 1998, 182) con el objeto de comprender e interpretar el mensaje. En este diálogo establece diferentes conexiones interculturales e intertextuales, desde las referencias folclóricas, histórico-literarias, lingüísticas, mitológicas, etc. La interacción de cada receptor con el texto literario, única e irrepetible, lo va construyendo progresivamente como lector, pero también funda paulatinamente su identidad a través de la apropiación afectiva de las obras. Esta doble articulación se gesta en el conocimiento de sí mismo y de la alteridad, a los que todo lector se aproxima mediante la literatura.

La conformación de la identidad a través del diálogo literario se produce, ya que tal y como nos explica Ballaz (2000, 13-14): "todos los textos son pistas por las que el lector va efectuando la construcción de su yo». Gracias a este proceso comunicativo, el lector adquiere los referentes culturales de la sociedad a la que pertenece, pero también se aproxima a las representaciones que ésta ha construido para explicar la diferencia y, por tanto, a todos los discursos discriminatorios y a los prejuicios extendidos como únicas interpretaciones válidas. La literatura supone, de esta manera, un poderoso instrumento de cohesión social, pues ofrece tanto a los lectores del grupo cultural mayoritario, como a aquellos provenientes de colectivos minoritarios, una cosmovisión común y un marco interdisciplinar para la conjunción de las distintas historias vitales y, a partir de éstas, la creación de una identidad plural.

Desde esta perspectiva, el desarrollo de la competencia literaria y la construcción del lector, comprendido como receptor activo y crítico, representan armas esenciales para el conocimiento de la alteridad y la generación de procesos de identificación con el otro existente en cada conjunto social, pero también para la exégesis crítica de toda ideología maniquea o racista subyacente tras cada imagen, tras cada asunción asumida sin reflexión previa.

La configuración del lector, finalidad última de la educación literaria, significa el germen de la ciudadanía activa y del sentimiento de pertenencia a través de 
la adquisición del código escrito y de la literatura como instrumento privilegiado desde su dimensión socializadora y cohesiva. La educación literaria desde la perspectiva intercultural permite leer el mundo y transformarnos paulatinamente en habitantes universales a medida que comprendemos la artificialidad de las fronteras geográficas o lingüísticas y la pertenencia a múltiples identidades (Ibarra y Ballester, 2010; Maalouf, 2008).

Desde esta conciencia, defendemos un destacado y progresivo protagonismo de la didáctica de las literaturas y de las lenguas, ya que mediante el texto literario podemos aproximarnos a todas las materias del currículum de las diferentes etapas con el objeto de regalar al alumnado los instrumentos cognoscitivos básicos para la comprensión de la realidad circundante. La educación literaria intercultural puede, de esta manera, trascender las estrechas fronteras de una única asignatura e instaurar un espacio de reflexión e intervención desde el que leer y habitar el mundo mediante la progresiva conversión de los lectores en ciudadanos activos y críticos con la realidad circundante (Ballester, 2007b; Evers, 2009; Ibarra y Ballester, 2010).

Desde nuestra óptica, la educación literaria en la sociedad contemporánea nos brinda la posibilidad de esbozar un amplio y complejo panorama para la interculturalidad. En efecto, la interculturalidad, comprendida como paso posterior a la multiculturalidad, y su relación con la literatura y con la literatura infantil y juvenil ofrecen un vasto ámbito de estudio y un extenso abanico de posibilidades, todavía no explotadas en profundidad.

Resulta, pues, una imperiosa necesidad reflexionar y mostrar las posibilidades didácticas, estéticas, cognoscitivas y lúdicas que nos brinda la literatura para la comprensión de nuestras sociedades plurales y, sobre todo, como fuente de aproximación entre las diferentes culturas que constituyen el mundo actual.

Desde esta perspectiva, la educación literaria como también la didáctica de la literatura adquieren una importancia fundamental en la sociedad contemporánea, puesto que nos permiten brindar al alumnado los instrumentos cognoscitivos esenciales para la comprensión de la realidad circundante, así como instaurar un espacio de reflexión crítica en torno a los diferentes discursos discriminatorios en ocasiones ocultos tras determinadas actitudes, a través de la literatura como herramienta fundamental de aproximación a la alteridad y a la diferencia como rasgo inherente a todo colectivo.

Propugnamos, pues, un destacado protagonismo en cuanto a la función de la didáctica de la literatura en el siglo xxI se refiere. En este proceso, el foco de interés esencial es la literatura, tanto como recurso didáctico y pedagógico de primer orden para aulas pluriculturales, como para la promoción de procesos de formación, análisis y reflexión del profesorado con enfoque intercultural.

La literatura, no lo olvidemos, regala una representación del mundo y una mirada sobre la realidad correspondiente al imaginario de valores y estereotipos de la sociedad que la produce. De esta forma, la literatura funda un espacio de reflexión a través de las voces de sus diferentes protagonistas, pero también desde sus silencios y ausencias más significativas. 


\section{EL CANON: ENTRE LAS COMPETENCIAS LITERARIA E INTERCULTURAL}

Todas las culturas han creado una literatura propia para interrogarse sobre el mundo, para reflejarse y para transmitir a las próximas generaciones su particular cosmovisión, su sistema de valores con todos sus mitos, imágenes, tópicos y personajes.

En nuestras investigaciones y proyectos ${ }^{1}$ hemos pretendido proporcionar una aproximación crítica a la literatura desde una perspectiva intercultural, conocer cuáles son las imágenes que pretendemos transmitir a los nuevos ciudadanos del siglo XXI mediante los textos literarios seleccionados para su aprendizaje, pero también desde aquellos «apropiados o ganados» por éstos y cuál es la ideología subyacente tras estos personajes o tópicos.

Desde nuestra perspectiva, la exégesis detallada de una serie de obras representativas del periodo contemporáneo puede permitirnos analizar la imagen que de la inmigración y, por extensión, de los movimientos migratorios están construyendo las diferentes sociedades. La aproximación a la figura del otro, a la alteridad desde la óptica de la diversidad cultural, la presencia o ausencia de determinados tópicos, personajes, claves, espacios, tiempos o la exclusión y el protagonismo de determinadas voces nos han permitido y nos permitirán desvelar la ideología subyacente en discurso literario y, por tanto, los valores que estamos legando a las diferentes generaciones en formación.

Anteriormente, hemos reseñado la relevancia de la literatura en la formación de los niños y adolescentes no sólo como instrumento educativo de primer orden, sino también como herramienta básica para la educación (Ballester, 2007a; Colomer, 1998 y 2010; Mendoza, 2009). De acuerdo con estas consideraciones, nuestras investigaciones contemplan no sólo la vertiente educativa de la literatura, sino su importancia como eje básico de la educación literaria, tal y como postulan los actuales currícula españoles, su impacto para la creación de futuros lectores y el desarrollo de la competencia específica, la literaria.

Asimismo, creemos que toda reflexión rigurosa debería partir, en primer lugar, de la definición de determinados conceptos y actitudes enmascaradas en posturas aparentemente positivas para la consideración de la diversidad cultural a partir del análisis crítico de los textos literarios. De hecho, existen algunos estudios que constatan toda una serie de carencias de urgente resolución en esta línea de investigación, tales como la ausencia de un consenso generalizado en torno a la terminología (Ballester, Ibarra, Mínguez y Morote, 2007) y la consecuente inexistencia de un panorama representativo de la interculturalidad en la literatura

1. Entre otros proyectos destacamos "Globalització, exclusió i multiculturalitat en Literatura Infantil i juvenil» dentro de la convocatoria de Acciones Especiales de la Universitat de València, referencia: UV-AE-20060713, "Diversidad y (des)igualdad en la literatura infantil y juvenil contemporánea (19902012)» referencia. UV-INV-PRECOMP13-115502 o «Educación literaria e Interculturalidad» del Ministerio de Ciencia e Innovación, referencia: EDU 2008-01782/EDUC. 
de los últimos años, de la ausencia de infraestructura (bases de datos, corpus...) o de herramientas consensuadas por la mayoría de especialistas (criterios para la selección de muestras, protocolos de análisis, estudios comparados del periodo y temática seleccionados...).

Por este motivo, defendemos la imperiosa necesidad de investigaciones rigurosas en las que: a) se analicen detalladamente los contenidos de las producciones literarias, tanto desde el punto de vista ideológico como literario; b) se genere la infraestructura de investigación necesaria desde la que seleccionar y analizar conjuntos de textos literarios con una metodología clara de carácter científico que evite la excesiva ideologización de la enseñanza; c) se diseñen herramientas de trabajo para aprovechar didácticamente estos contenidos desde la perspectiva de las competencias básicas (lectora, literaria, intercultural, aprender a aprender, artística, social y ciudadana...) y el placer lector.

Una parte de la obra crítica de Harold Bloom (1994, 1998, 2000 y 2004) ha provocado un debate sobre el canon literario -diríamos que bastante interesante en algunos aspectos- sobre todo en un mundo, a veces, tan cerrado y tan poco receptivo a la pluralidad de opiniones como es el académico. Por nuestra parte, consideramos en principio positivos tales debates, al menos por la diversidad de puntos de vista esgrimidos; si bien, no debemos olvidar que la postura de Bloom, en realidad, esconde un prejuicio marcadamente reaccionario y su discurso nace desde la autoridad literaria en mayúsculas, muy cerca de la infalibilidad. En este sentido, Vilaseca afirma:

És aquí on comença a fer-se evident la importància del que es juga quan es tracta d'esbrinar qui té el control de les definicions i de les adjudicacions en l'àmbit tant de la cultura en general com de la literatura en particular. Perquè si, d'una banda i com ha apuntat Said, la noció elitista i etnocèntrica de la cultura defensada per Mathew Arnold és la base de les polítiques més imperialistes i racistes de l'Europa del segle XIX [...] aquesta noció de cultura és la responsable de la promoció i la imposició d'una literatura occidental com $a$ «literatura pròpiament dita» i com a superior a la de l'Orient colonitzat, de l'altra és aquesta mateixa noció la que, ara des de de l'interior mateix de la tradició occidental, ha portat a terme amb una contundència i una agressivitat similars la tasca de localització, desautorització i subordinació de l'Altre respecte del que es considera "propi, natural'i superior» en una cultura determinada $(1997,48)$.

En última instancia, sin embargo, por muchos mapas, jerarquías o cánones marcados por la crítica y la historia sobre la literatura, nos corresponde a nosotros, los lectores y los docentes, la única mediación de nuestra experiencia literaria o artística. Los cánones magistrales dejarán progresivamente de percibirse como un itinerario neutral y, en este sentido, podrá cuestionarse el carácter exclusivamente estético de los criterios que lo fundamentan. Sin olvidarnos, por supuesto, de su marcado cariz ideológico.

En esta línea, Vilaseca ofrece un contundente análisis de los problemas inherentes a la concepción del canon occidental como un canon único para los sujetos 
que tradicionalmente han sido marginados de su diseño. Por una parte, este investigador apunta la exclusión de la experiencia de estos sujetos respecto de la consideración de "universal», "central» o incluso, en ocasiones, de la "Cultura» en mayúsculas. Si bien constata que en aquellos casos en los que estos sujetos no han sufrido la ausencia del canon se ha optado por su denigración a través de adjetivos que niegan su "centralidad" y, directamente relacionado con estos términos, explica el rápido surgimiento de otros calificativos como literatura "política", "minoritaria", "exótica" o "radical». Por otra parte, la existencia de un canon como el defendido desde posiciones monoculturalistas ha provocado la imposibilidad de acceso a unos modelos y tradiciones en los que las experiencias de estos sujetos marginados se vean representadas con mayor fidelidad, tanto para sí mismos como para los otros. Como consecuencia práctica de este obstáculo podemos destacar las diferentes revisiones y las búsquedas iniciadas con la finalidad de documentar y revalorizar literaturas menospreciadas o silenciadas por los discursos culturales hegemónicos.

Asimismo, de igual forma que podemos verificar la existencia de un canon literario en términos generales como los que venimos esbozando, también podemos constatar la existencia de un canon literario escolar que opera con mecanismos similares al primero. De hecho, de acuerdo con Bombini (1996, 8), éste se constituye en centro y "metrópolis desde la que operan los contrastes para el reconocimiento de los otros".

Uno de los principales problema de este diseño para la praxis educativa estriba, a nuestro juicio, en el estatismo de la programación de lecturas de aula y requiere, por tanto, de la necesaria apertura y la renovación del carácter conservadoramente estático regulado a través de los programas docentes. De la misma manera, en esta configuración de lecturas ya instituida influye además de forma poderosa el concepto de literatura que posee cada docente, tal y como se puede observar, por ejemplo, en las diversas vicisitudes sufridas por la literatura infantil y juvenil históricamente hasta su incorporación en fechas relativamente recientes a la escuela y a la universidad.

Pensemos a tal efecto que pese a la integración de la literatura infantil y juvenil en el currículo y el común acuerdo existente respecto a su importancia en la educación literaria, en su consideración todavía pesan un gran número de prejuicios de antaño, reflejados en definiciones de la LIJ como literatura menor o de segunda fila respecto a las "grandes obras". Así, por ejemplo, docentes con gran formación literaria se ubican en una posición ambigua respecto a su calidad e importancia, al amparo de una óptica de incredulidad como único argumento. Como también, gran parte del ámbito académico reproduce este escepticismo respecto a la LIJ mediante dos posturas opuestas, bien a través de su olvido sistemático, bien mediante comentarios, con gran frecuencia, despectivos. Reproducimos a tal efecto las aseveraciones de Bombini (1996, 9): «Desde la historia de aquellos géneros que la gran historia de la literatura no consideró, como la historieta, el melodrama, el folletín, e incluso, el policiaco, la ciencia ficción y la literatura infantil, hasta las 
exclusiones por explícitas censuras políticas, ideológicas y estéticas, muchos textos fueron alguna vez otros".

La búsqueda de la estrategia más adecuada para repensar y, al tiempo, permitir abrir a nuevas propuestas la impermeabilidad del canon se convierte en un imperativo de inexcusable atención en la educación literaria contemporánea. Un abanico de textos plurales de diversas realidades culturales debe asaltar la homogénea construcción cultural que el canon pretende forjar y difundir como única válida para las sociedades occidentales (Ibarra y Ballester, 2014).

En este sentido, en cuanto al panorama actual de la LIJ en España, creemos que uno de los aspectos más positivos procede de la aparición y la posterior generalización del plurilingüismo. En nuestros días, un número considerable de los libros publicados en alguna de las cuatro lenguas oficiales se edita al mismo tiempo o con relativa rapidez en las otras tres lenguas. La consecuencia directa, por tanto, estriba en el intercambio tanto de autores como de temáticas, estilos y enfoques de gran interés que permite el conocimiento de realidades diferentes de la propia y fomenta la educación intercultural a partir del texto literario. Como muestra significativa de los positivos efectos de esta tendencia, podemos apuntar el inicio todavía tímido, pero incipiente, de la edición de libros en alguna de las lenguas cooficiales y, al mismo tiempo, su traducción en el mismo ejemplar a otras lenguas, como el árabe o el chino.

Nuestra defensa, por tanto, de la configuración de un canon de aula necesariamente plural, heterodoxo e interdisciplinar parte de la asunción de una premisa básica: la necesidad de la integración de contenidos y materiales en los procesos de enseñanza-aprendizaje adecuados y coherentes para el desarrollo de objetivos de vital importancia como la formación de lectores críticos y ciudadanos de sociedades democráticas en las que no impere la desigualdad como único principio organizador posible.

Estas aseveraciones no implican el privilegio de la selección de textos obsoletos para estos incipientes lectores, sino que, por el contrario, abogan por la reivindicación de un corpus necesariamente diverso y, sobre todo, fomentan el empleo consciente de estrategias de mediación de estos textos literarios desde las que promover marcos interpretativos plurales para la construcción del sentido del mundo y el desarrollo de la competencia literaria y lectora. Por este motivo, nuestra concepción de la educación literaria e intercultural no se fundamenta en un canon constituido de forma exclusiva por los denominados clásicos, sus reediciones o las distintas obras consideradas canónicas por la historia literaria, sino que consideraremos todo tipo de texto presente actualmente en la enseñanza de la literatura (Ibarra, 2007). 


\section{LA LITERATURA COMPARADA: UNA METODOLOGÍA POSIBLE PARA LA EDUCACIÓN LITERARIA E INTERCULTURAL}

Ante las hipótesis y objetivos de trabajo anteriormente diseñados, la metodología necesaria para llevarlos a buen término se ubica forzosamente en un marco interdisciplinario. Pese al creciente interés por la enseñanza de la literatura y la preocupación por la lectura reflejada en los nuevos currículums a través del diseño de las competencias básicas y la articulación del Plan de Fomento de la Lectura, todavía no contamos con estudios rigurosos en los que se describa la educación literaria desde una perspectiva intercultural referidos a nuestro ámbito geográfico, como tampoco trabajos que incorporen las reflexiones de la investigación más reciente a este respecto en cuanto a otros países y que efectúen un balance certero de la situación actual.

Anteriormente hemos anotado la relevancia de la didáctica de las literaturas y las lenguas como espacio de acción educativa e integración de diferentes disciplinas. Sus propósitos se corresponden con el conjunto de formulaciones explícitas y valores que la sociedad atribuye a la enseñanza de la lengua y la literatura de acuerdo con las expectativas en torno a los conocimientos lingüísticos que deben poseer los ciudadanos. Estos extensos objetivos se encuentran compartidos con las diferentes áreas y están presentes en la transmisión/asimilación de los saberes que repercuten en los contenidos y en el desarrollo de todo el currículum escolar (Ballester, 2007a; Evers, 2009).

En este sentido, la inclusión del enfoque comparativo nos proporciona un amplio abanico de opciones para la enseñanza de la literatura y además, tal y como apuntan Mendoza (1994), Ballester e Ibarra (2008), resulta particularmente útil en el Estado español, con diferentes comunidades autónomas con dos lenguas propias y oficiales. La metodología de la literatura comparada incrementa notablemente el espectro de estrategias e instrumentos didácticos y permite, así, la superación de las fronteras geográficas y lingüísticas, dado que éstas no deben coincidir forzosamente con las literarias. De esta forma, se trasciende la restrictiva parcelación del conocimiento literario en torno a una única literatura para conectarla con la cultura de otras comunidades sociales en un momento sociohistórico concreto.

Desde esta perspectiva necesariamente plural, la literatura que brindamos al alumnado, como también la metodología para su enseñanza, puede resquebrajar los límites conceptuales de etiquetas clasificatorias de obras, autores y movimientos para permitir en el aula la irrupción de otras culturas y literaturas diferentes de la occidental (Ibarra y Ballester, 2010).

Por este motivo, a lo largo del presente artículo hemos pretendido aproximarnos a la educación literaria y su relación con la interculturalidad y la formación de sociedades plurales y democráticas, sin olvidar la vertiente fruitiva que la literatura y la lectura conllevan para su receptor. La literatura regala a cada lector una experiencia placentera y única desde la que preguntar a cada sujeto qué sabe de sí mismo y del otro, un lugar privilegiado de conocimiento del legado cultural y lingüístico de la sociedad, la posibilidad de subrayar la percepción de la diferencia 
cultural y la mutilación de ésta en la percepción de la alteridad. En el contexto actual, el estudio del hecho literario desde una perspectiva necesariamente interdisciplinar nos permite deconstruir actitudes discriminatorias y avanzar en el compromiso intercultural que la educación nos plantea.

\section{UNA PROPUESTA DE LECTURAS PARA LA EDUCACIÓN LITERARIA E INTERCULTURAL}

Con el objetivo de ilustrar el planteamiento teórico que venimos desarrollando, ofreceremos a continuación una propuesta de lecturas literarias en modo alguno exhaustiva o excluyente, sino a modo de ejemplo para la necesaria renovación del canon escolar a través de un corpus plural, diverso e intercultural, tal y como hemos defendido en nuestro trabajo.

Con esta finalidad, hemos diseñado una propuesta compuesta por 26 obras que recorren los niveles educativos de Educación Infantil, Primaria, Secundaria y Bachillerato. Su clasificación de títulos responde, por tanto, a las etapas educativas anteriores, dada también su correspondencia con las denominadas edades lectoras y las franjas de edad más repetidas en las recomendaciones bibliográficas. Para cada etapa hemos seleccionado ocho obras, con la excepción de Secundaria y Bachillerato, puesto que al incluir dos niveles de escolaridad de gran relación en cuanto a intereses lectores y posibilidades de comprensión de textos de cada vez mayor complejidad, hemos considerado más conveniente considerarlas en una única franja y, por tanto, distinguirla con un número ligeramente más elevado de títulos que, no obstante, no descompensara la propuesta, 10 en este caso.

En cuanto a las etapas lectoras, debemos asimismo puntualizar que hemos seleccionado textos que pueden ser comprendidos «a partir de» y cuyas posibilidades de lectura no se agotan en esa etapa educativa. Pensamos que la lectura literaria debe despertar el interés de su lector y, al tiempo, diseñar y construir un lector crítico, capaz de ir progresivamente más allá en la construcción del sentido. Por este motivo, nuestro corpus requiere la implicación activa de su lector para la comprensión de su significado y no sólo una lectura literal de sus páginas e incluso, en ocasiones, también solicita la participación del mediador adulto, sobre todo, en las etapas iniciales de la formación lectora y literaria.

A partir de las premisas anteriores de partida, en su confección se han considerado diferentes criterios, en primer lugar, la necesaria calidad literaria, pero también se ha atendido a la conjunción de los siguientes factores en su elección: a) la diversidad de géneros y tipologías textuales; b) la diversidad lingüística; c) la diversidad temática.

De esta forma, nuestra propuesta aboga por la diversidad en un triple sentido, en un primer lugar, en cuanto a las distintas posibilidades temáticas se refiere. Por este motivo, en este corpus se reúnen títulos muy diferentes que permiten una aproximación a la diversidad desde una perspectiva en modo alguno restrictiva, por lo que se aprecian tanto obras que abordan los movimientos migratorios en sus diferentes vertientes, pasando por las adopciones internacionales, el racismo, el 
miedo a los otros, la tolerancia, el encuentro entre culturas: la de procedencia y la de acogida o la diversidad familiar, afectiva y sexual hasta el tópico del viaje como estrategia de descubrimiento de realidades diferentes de la propia.

En segundo lugar, de acuerdo con la diversidad lingüística preconizada, hemos seleccionado libros que se encuentren en más de una de las lenguas oficiales del Estado español, de hecho, una parte importante de los textos figura en ediciones disponibles en la mayoría de estas lenguas. Como también hemos considerado obras pertenecientes a autores que no se enmarcan en etiquetas nacionales de procedencia, con la finalidad de mostrar diferentes maneras de ver la realidad circundante a través de la ficción.

En tercer lugar, hemos atendido a los diversos géneros y tipologías textuales que deben tener presencia en la educación lectora y literaria de los niños y jóvenes, pues con frecuencia se privilegia la narrativa, ya sea el cuento o la novela en función de la edad lectora, en detrimento de otros géneros fundamentales como la poesía o el teatro. Asimismo, en este sentido, nuestra propuesta apuesta por géneros considerados no canónicos, o si se prefiere "periféricos» en la educación literaria, dado el escaso número de ocasiones que figuran en las listas de lecturas de aula, pese al tácito acuerdo entre los especialistas y los profesores sobre su relevancia y necesaria inclusión. Nos referimos, por ejemplo, al ensayo y al cómic o novela gráfica, representados a través de una muestra de títulos significativos. Por último, nuestro corpus contempla también los géneros de reciente creación que progresivamente adquieren importancia en la oferta destinada a niños y jóvenes y que ha despertado el interés de la crítica especializada: el álbum.

Por último, nuestra selección siempre ha tenido presente la necesaria calidad de las obras, pues existen numerosos títulos que responden a la conjunción anterior de factores sin perder de vista la calidad literaria, fundamental para garantizar también las experiencias estéticas de los lectores en formación. El respeto a este criterio no solo estriba en el punto de vista de los investigadores de este trabajo, sino también en otras fuentes de prestigio, como, por ejemplo, las recomendaciones efectuadas por el Servicio de Orientación de Lectura, con diferentes especialistas y expertos en la recomendación de libros por edades para ofrecer una selección bibliográfica de calidad. Asimismo, un gran número de las obras elegidas han obtenido diferentes galardones tanto estatales como internacionales que refrendan, junto al resto de criterios, su indudable calidad.

\subsection{Educación Infantil}

La lectura constituye uno de los elementos fundamentales para el alumnado en esta etapa, dado que no sólo les permite iniciarse en el aprendizaje del código escrito, sino, sobre todo, aproximarse a diferentes modelos e historias desde las que comprender mejor la sociedad en la que progresivamente van a insertarse. Por este motivo, hemos combinado diferentes géneros (narración, canciones, retahílas, adivinanzas, álbum...) con atractivas temáticas que contemplan la diversidad desde 
diferentes ópticas, desde la adopción a partir de personajes animales, pasando por la tradición oral de culturas diferentes a la propia, el color de la piel o los nuevos modelos familiares.

Chen, Chih-Yuan (2005) Guyi Guyi. Barcelona, Thule.

Desclot, Miquel (2013) El blanc i el negre. Barcelona, La Galera.

ERLICH, Bernado (2005) El color de mi familia. Bilbao, Editorial A Fortiori.

Favret, Hafuda y Lerascle, Magdeleine (2005) A la sombra del olivo. Madrid, Kókinos.

KaTZ, Karen (2005) Los colores de nuestra piel. Barcelona, Intermón Oxfam.

PietPer, Cristiane (2000) Sin rumbo por el mundo, Catalina y el Oso. Pontevedra, Kalandraca.

Ravishankar, Anushka (2008) Los elefantes nunca olvidan. Barcelona, Thule.

Rivera Ferner, Marta (2006) Una perla para Yamila. Valencia, Editorial Brosquil.

\subsection{Educación Primaria}

En esta etapa de ostensibles diferencias lectoras en función del ciclo educativo, las obras seleccionadas abordan ya perspectivas un poco más complejas en el tratamiento de la diversidad como las adopciones internacionales, las familias de acogida o la mirada del otro a través de diferentes géneros.

CAPDEVILA, Roser (2006) Les Tres Bessones y el planeta Formatge. Barcelona, Icaria/Intermón Oxfam.

CARBAlleIra, Paula (2006) Smara. Sevilla, Kalandraka.

GarCíA, Graciela (2005) Wamba y el viaje de la miel. Madrid, Demipage.

Kadohata, Cynthia (2006) Kira-Kira. León, Everest.

Martín Garzó, Gustavo (2007) Un regalo del cielo. Madrid, sm.

PEYDRó, Eva (2002) Les vacances de Saïda. Alzira, Bromera.

Sснмітт, Eric-Emmanuel (2006) El señor Ibrahim y las flores del Corán. Barcelona, Obelisco. SOTORRA, Andreu (2003) Kor de parallamps. Barcelona, Edebé.

\subsection{Educación Secundaria y Bachillerato}

Dadas las posibilidades del lector en esta etapa, el corpus plantea, a través de géneros como el ensayo, el teatro, la narrativa, el cómic o la novela gráfica, temáticas de gran complejidad como la inmigración, el racismo y la tolerancia, los conflictos bélicos entre Palestina y Israel o la educación para la igualdad de género.

Alapont, Pasqual (2003) L'infern de Marta. Alzira, Bromera.

Atxaga, Bernardo (2000) Cuentos apátridas. Barcelona, Ediciones B.

BEnAVIDES, Jorge et al. (2005 y 2006) Inmenso estrecho: cuentos sobre la inmigración. Madrid,

Kailos, vols. 1 y 2.

Ben Jelloun, Tahar (2000) Papá: ¿qué es el racismo? Barcelona, Alfaguara. 
Benlloch, Kike y Vázquez, A. (2002) Freda. Onil, Edicions del Ponent. KERR, Judith (2004) Cuando Hitler robó el conejo rosa. Madrid, Alfaguara. Molins, Manuel (2004) Abú Magrib. Alzira, Bromera. PÁEZ, Enrique (1995) Abdel. Madrid, sM. SATRAPI, Marjane (2009) Pérsepolis. Barcelona, Norma. TAN, Shaun (2006) Emigrantes. Cádiz, Barbara Fiore.

\section{CONSIDERACIONES FINALES}

La educación intercultural y la adquisición y el desarrollo de la competencia intercultural ligados a la educación literaria inauguran un nuevo periplo de investigación y de actuación en el currículo de los diferentes niveles educativos. Desde esta perspectiva, la enseñanza de la literatura puede trascender los límites restrictivos que encarcelan los textos en una única cultura y la vinculan, por tanto, a un país determinado y a una comunidad de referencia.

Frente al enfoque historicista, vinculado a taxonomías compartimentales en torno a obras, autores y movimientos, la educación literaria e intercultural promueve un enfoque necesariamente plural y comparatista. Este planteamiento resquebraja las fronteras de un canon de aula excesivamente tradicionalista y, en la mayoría de ocasiones, marcadamente occidental para escuchar y leer todas aquellas voces diferentes al grupo social hegemónico.

Como ponen de manifiesto diferentes estudios e investigaciones, desde diferentes puntos de vista y disciplinas (Aguado, 2003; Bernabé, 2012; Besalú y Tort, 2009; Ibarra y Ballester, 2011; Leiva, 2011; Portera, Dusi y Guidetti, 2010; Sleeter, 2005; Soriano, 2008 y 2009) la educación intercultural e inclusiva es una propuesta crítica y reflexiva con una gran potencialidad para el profesorado, pero su transformación práctica resulta compleja, a veces con ambigüedades e incluso con contradicciones que nos conducen a repensar la multiculturalidad y el plurilingüismo desde diferentes ópticas y metodologías. Creemos que esta diversidad de posturas, de maneras de enfrentarse a estas nuevas realidades no pueden considerarse en modo alguno negativas, sino que resulta esencial construir y reconstruir en el ámbito de la docencia unos espacios de diálogo social y cultural en el sentido más profundo del término.

La composición multicultural de las aulas requiere forzosamente de otros marcos epistemológicos de referencia desde los que valorar la diversidad cultural como fuente de enriquecimiento y de aproximación a la diferencia despojada de estereotipos y prejuicios. La literatura, en un sentido amplio y plural, brindada a los discentes funda este espacio de reflexión y comunicación desde el que cada ser humano puede dialogar con las generaciones anteriores y futuras, así como con las coetáneas, ya sean éstas de su grupo social de procedencia, como de aquellas diferentes a la propia. Gracias a este diálogo, los receptores de los textos se convierten en habitantes comprometidos con la realidad circundante y en pleno 
ejercicio de sus derechos y obligaciones: el lector se transforma en el ciudadano de una sociedad digna de ser denominada multicultural.

No olvidemos que la literatura en cada una de sus variantes y maneras de entenderla se nos presenta como una herramienta fundamental y eficaz para el acercamiento al otro, pues, entre otras funciones, nos ayuda a transmitir el valor de la diversidad y de la diferencia. En consecuencia, la lectura literaria efectúa un papel esencial en la edificación de las identidades, pues, recordemos que la literatura ayuda a explicar el mundo que rodea al individuo en la construcción de los procesos de pertenencia e identificación (nacional, cultural, social, universal...) y, por tanto, su propia ciudadanía. No debemos olvidar que la identidad personal procede del encuentro de múltiples identidades colectivas y, al mismo tiempo, personales, configuradas por aportaciones de diversas culturas, efecto de los intercambios producidos por la globalización y, por extensión de ésta, los movimientos migratorios. En una sociedad como la contemporánea, se precisa el desarrollo de una identidad flexible y versátil que permita al ser humano afrontar cada una de las transformaciones a las que tiene que enfrentarse y cada vez con más celeridad a lo largo de su vida (Bernal, 2005 y 2011; Todorov, 2008). La educación literaria desde la perspectiva intercultural puede ayudar a diseñar, así, un espacio dialógico desde el que todo ser humano puede conocer, pensar, soñar y construir sociedades democráticas posibles.

\section{REFERENCIAS BIBLIOGRÁFICAS}

Aguado, M. T. (2003) Pedagogía intercultural. Madrid, McGraw-Hill.

ARnÁiz, P. y Escarbajal, A. (2012) Reflexiones sobre cultura, identidad y racismo desde una mirada pedagógica. Teoría de la Educación. Revista Interuniversitaria, 24, 83-106.

Ballaz, J. (2000) Lectura e identidad. Primeras Noticias. Revista de Estudios Literarios, 171, 11-14.

BAllester, J. (2007a) L'educació literària. Valencia: SPU.

BALlester, J. (2007b) La educación literaria, el canon y la interculturalidad. Primeras Noticias. Revista de Estudios Literarios, 224, 15-19.

BALLESTER, J. e IBARRA, N. (2008) Literatura comparada y educación: una aproximación crítica, Lenguaje y Textos, 28, 11-19.

Ballester, J.; Ibarra, N.; Mínguez, X. y Morote, P. (2007) Aproximación a un glosario sobre educación literaria intercultural. Lenguaje y Textos, 26, 205-228.

BARTolomé, M. (2001) Identidad y ciudadanía en adolescentes. Nuevos enfoques desde la ciudadanía intercultural, en SORIANO, E. (coord.) Identidad cultural y ciudadanía intercultural. Madrid, La Muralla, 75-107.

Bernabé, M. M. (2012) Importancia de la música como medio de comunicación intercultural en el proceso educativo. Teoría de la Educación. Revista Interuniversitaria, 24, 107-127.

BERNAL, A. (2005) Reconceptualización de la identidad personal y educación para la autodeterminación posible. Teoría de la Educación. Revista Interuniversitaria, 17, 97-128.

Bernal, A. (2011) Postmodernización y Educación. Notas para el debate de una narrativa pedagógica centrada en la identidad. Educación XXI, 14, 285-302. http://dx.doi. org/10.5944/educxx1.14.2.255. 
JOSEP BALLESTER ROCA Y NOELIA IBARRA RUIS

LA FORMACIÓN LECTORA Y LITERARIA EN CONTEXTOS MULTICULTURALES. . .

Besalú, X. y TORT, J. (2009) Escuela y sociedad multicultural. Sevilla, MAD.

Bloom, H. (1994) The Western Canon: The Books and School of the Ages. New York, Harcourt Brace.

Bloom, H. (1998) Shakespeare: The Invention of the Human. New York, Riverhead Books.

Bloom, H. (2000) How to Read and Why. New York, Scribner.

Bloom, H. (2004) The Best Poems of the English Language: From Chaucer Through Frost. New York, Harpen Collins.

Bombini, G. (1996) Las otras literaturas/otras culturas: un problema pedagógico. Textos, 9 , 7-14.

CANTO, A. C. (2003) Educación inclusiva: una percepción diferente de la diversidad, en REYZÁBAL, M. V. (dir.) Perspectivas teóricas y metodológicas: lengua de acogida, educación intercultural y contextos inclusivos. Madrid, Consejería de Educación, 97-109.

CIDE (2007) El alumnado extranjero en el sistema educativo español. Boletín CIDE de Temas Educativos, 16, MEc. Consultado el 24 de marzo de 2014. http://redined.mecd.gob.es/ xmlui/bitstream/handle/11162/62100/00820092000084.pdf?sequence=1.

Colomer, T. (1998) La formación del lector literario. Madrid, Fundación Germán Sánchez Ruipérez.

Colomer, T. (2010) Introducción a la literatura infantil y juvenil actual. Madrid, Síntesis.

Dearden, C. D. (1994) Con los otros. La Gaceta del Fondo de Cultura Económica, 288, 30-35.

Delors, J. (1996) La educación encierra un tesoro. Informe de la Unesco de la Comisión Internacional sobre la educación para el siglo XXI. Madrid, Santillana/Unesco.

EwERs, H. (2009) Fundamental concepts of children's literature research: literary and sociological approaches. New York, Routledge.

GIMENO SACRISTÁN, J. (2001) Educar y convivir en la cultura global. Madrid, Morata.

IBARRA, N. (2007) ¿Literatura infantil y juvenil e interculturalidad? Una mirada a la LIJ contemporánea. Primeras Noticias. Revista de Estudios Literarios, 224, 21-29.

IBARRA, N. (2008) La literatura infantil y juvenil ante el reto de la interculturalidad, en Rössing, T. M. K. y RetTenmeier, M. (orgs.) Lectura de los espacios y espacios de lectura. Passo Fundo, Universidade de Passo Fundo, 330-348.

IbarRA, N. y BALLeSter, J. (2010) La educación literaria e intercultural en la construcción de la ciudadanía. Aula de Innovación Educativa, monográfico «Educación literaria e Intercultural» coordinado por Ibarra, N. y Ballester, J., 197, 9-13.

IbARRA, N. y BALlester, J. (2014) ¿Crónica de un divorcio anunciado?: la enseñanza de la literatura y la lectura en el siglo XXI, en CAMPOS, M. y MARTOS, E. (coords.) Cartografías lectoras y otros estudios de lectura. Madrid: Marcial Pons.

LeIva, J. J. (2011) La educación intercultural en una encrucijada de caminos: reflexiones pedagógicas para la construcción de una escuela intercultural. Espiral. Cuadernos del Profesorado, vol. 4 (7), 43-56.

MaAlouf, A. (2008) Identidades asesinas. Madrid: Alianza.

Malgesini, G. y Giménez, C. (2000) Guía de conceptos sobre migraciones, racismo e interculturalidad. Madrid, La Catarata.

MENDOZA, A. (1994) Literatura comparada e intertextualidad. Madrid, La Muralla.

Mendoza, A. (coord.) (2009) Conceptos clave en didáctica de la lengua y la literatura. Barcelona, SEDLL/ICE/Horsori.

Ministerio de Educación, Cultura y Deportes (2013) Las cifras de la Educación en España. Consultado el 24 de marzo de 2014. https://www.mecd.gob.es/dms-static/d32d4b272827-446f-a0b6-3379dae1ad03/e4-12-xls.xls. 
Ministerio de Empleo y Seguridad Social (2013) Extranjeros residentes en España. Consultado el 24 de marzo de 2014. http://extranjeros.empleo.gob.es/es/Estadisticas/operaciones/con-certificado/201306/Residentes_Principales_Resultados_30062013.pdf.

Ministerio de Trabajo e Inmigración (2010) Extranjeros residentes en España. Consultado el 24 de marzo de 2014. http://extranjeros.empleo.gob.es/es/Estadisticas/operaciones/ con- certificado/201012/Principales_Resultados_31122010.pdf.

NAÏr, S. (2010) La Europa mestiza. Inmigración, ciudadanía, codesarrollo. Barcelona, Galaxia Gutenberg.

Portera, A.; Dusi, P. y GuidetTi, B. (2010) L'educazione interculturale alla cittadinanza. Roma, Carocci.

RodríGuez, F. y García, L. M. (2008) Identidad y ciudadanía: reflexiones sobre la construcción de identidades. Barcelona, Horsori.

Sales, A. y García, R. (1997) Programas de educación intercultural. Bilbao: Desclée De Brouwer.

SHORT, K. G. (2009) Critically Reading the Word and the World Building Intercultural Understanding through Literature. Bookbird: A Journal of International Children's Literature, 47, 1-10.

SLEETER, C. E. (2005) Un-standardizing curriculum: Multicultural teaching in the standardsbased classroom. New Cork, Teachers College Press.

SORIANO, E. (2008) Educar para la ciudadanía intercultural y democrática. Madrid, La Muralla.

SORIANO, E. (2009) Vivir entre culturas: una nueva sociedad. Madrid, La Muralla.

TODOROv, T. (2008) El miedo a los bárbaros. Barcelona, Galaxia Gutemberg.

VilaseCA, D. (1997) Consideracions sobre el problema del cànon a la crítica literària actual. Serra d'Or, 445, 47-49. 